\title{
Effect of levosimendan on myocardial contractility, coronary and peripheral blood flow, and arrhythmias during coronary artery ligation and reperfusion in the in vivo pig model
}

\author{
E du Toit, D Hofmann, J McCarthy, C Pineda
}

\begin{abstract}
Objective-To determine whether levosimendan, a calcium sensitiser that facilitates the activation of the contractile apparatus by calcium, improves myocardial contractile function during severe ischaemia and reperfusion without exacerbating the incidence of arrhythmias.

Design-Pigs were pretreated orally twice daily for 10 days with $0.08 \mathrm{mg} / \mathrm{kg}$ levosimendan or placebo. On day 11 the left main coronary artery was ligated for 30 minutes, followed by 30 minutes of reperfusion. A bolus dose of levosimendan, $11.2 \mu \mathrm{g} / \mathrm{kg}$ intravenously, or placebo was given 30 minutes before coronary ligation, followed by a continuous infusion of $0.2 \mu \mathrm{g} / \mathrm{kg} / \mathrm{min}$ levosimendan or placebo for the remainder of the experiment.

Results-During the ischaemic period, cardiac output was higher in the levosimendan group than in the placebo group (mean (SD): $2.6(0.5) v 2.0(0.2) 1 / \mathrm{min}, \mathrm{p}<0.05$ ) and systemic vascular resistance was lower (2024 (188) $v 2669(424)$ dyne. $\left.\mathrm{s}^{-1} \cdot \mathrm{cm}^{-5}, \mathrm{p}<0.005\right)$. During reperfusion, cardiac output and contractility $\left(\mathrm{LV}_{\max } \mathrm{dP} / \mathrm{dt}(\mathrm{pos}), 956\right.$ (118) $v 784$ (130) $\mathrm{mm} \mathrm{Hg} / \mathrm{s}, \mathrm{p}<0.05$ ) were increased by levosimendan. The incidence of ischaemic ventricular fibrillation and tachycardia was similar in the two groups but there were more arrhythmic events (ventricular tachycardia and ventricular fibrillation) in the levosimendan treated group $(8 / 12$ levosimendan $v 1 / 9$ control $p=0.05)$. Conclusions-Levosimendan improved cardiac output and myocardial contractility during coronary artery ligation and reperfusion. However, it increased the number of arrhythmic events during ischaemia in this model of in vivo regional ischaemia.

(Heart 2001;86:81-87)
\end{abstract}

Keywords: calcium sensitisers; myocardial ischaemia; arrhythmias

Conventional inotropic agents increase myocardial cyclic adenosine monophosphate (cAMP), either by stimulation of the $\beta$ adrenoreceptor pathway or by phosphodiesterase inhibition. Raised cAMP concentrations result in an increase in intracellular calcium which may exacerbate ischaemia/reperfusion calcium overload $^{1}$ (fig 1) and promote ventricular arrhythmias, not only during myocardial ischaemia ${ }^{2}{ }^{3}$ but also during reperfusion. ${ }^{4}$ During myocardial ischaemia, the contractile apparatus can be desensitised to calcium by intracellular proton accumulation (from glycolysis) or by an increase in cAMP dependent phosphorylation of troponin I. ${ }^{5}$ Calcium sensitisers could therefore be particularly useful in the setting of ischaemia and reperfusion to improve left ventricular contractile function, provided that a proarrhythmic effect can be excluded.

There have been numerous studies on the effects of traditional calcium sensitisers, such as MCI 154, EMD 57033, and EMD 60263, on the function of the postischaemic heart, ${ }^{6-8}$ but levosimendan has been little studied in the heart in vivo. Levosimendan is a calcium sensitiser which facilitates the activation of the contractile apparatus by calcium..$^{9-11}$ It is unique in that it not only increases the affinity of troponin C for calcium, but its affinity for troponin $\mathrm{C}$ is also calcium dependent. The implications of this characteristic of levosimendan are that it does not impair diastolic relaxation like most of the traditional calcium sensitisers. ${ }^{10}$ Electrophysiological studies have also shown that levosimendan opens the adenosine triphosphate

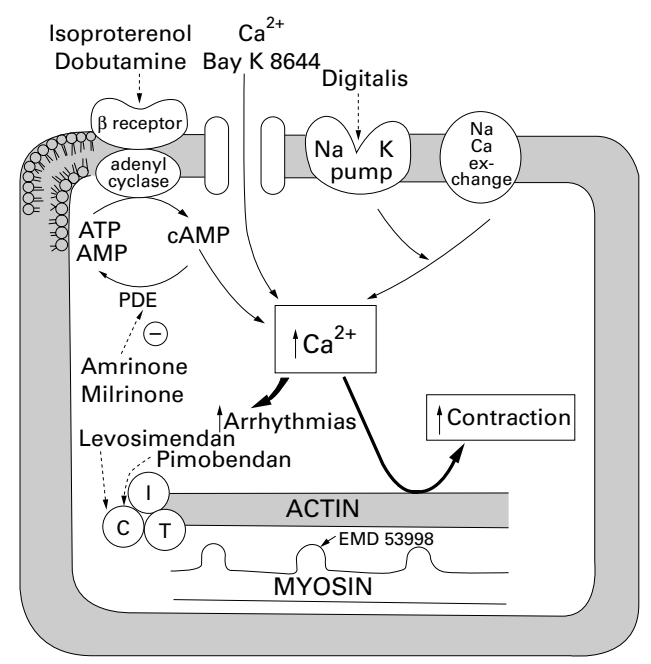

Figure 1 Site of action of various inotropic agents. Most of the conventional inotropes increase cyclic adenosine monophosphate (cAMP), with a subsequent increase in intracellular calcium ion concentration which enhances contraction. However, increased calcium ion concentrations may promote arrhythmias, particularly during ischaemia and reperfusion. Calcium sensitisers such as levosimendan, pimobendan, and EMD 53998 may enhance myocardial contraction without increasing intracellular calcium ion concentration and the associated risk of increased arrhythmias. AMP, adenosine monophosphate; ATP, adenosine triphosphate; $P D E$, phosphodiesterase. 
(ATP) sensitive potassium channel in ventricular myocytes ${ }^{11}$ and vascular smooth muscle cells, ${ }^{12}$ which may also provide it with antiischaemic properties.

Clinical studies have investigated the inotropic effect of levosimendan on failing heart muscle strips ${ }^{13}{ }^{14}$ and on reperfused hearts after coronary artery bypass grafting. ${ }^{15}$ The former studies showed a levosimendan induced improvement in muscle strip contractile function, while the latter demonstrated a levosimendan induced increase in cardiac output and coronary flow in these hearts. Nijhawan and colleagues ${ }^{16}$ recently measured cardiac output and the incidence of arrhythmias in patients after cardiopulmonary bypass surgery. They confirmed our findings,${ }^{17}$ showing that levosimendan improved cardiac function without increasing the incidence of arrhythmias in hearts subjected to global ischaemia. There is, however, no information concerning the effects of levosimendan on contractility and the incidence of arrhythmias in the regionally ischaemic and reperfused heart.

We propose that levosimendan may improve ischaemic and reperfusion function in an in vivo open chest pig model. To investigate this, we assessed the effects of this agent on myocardial function, the incidence of arrhythmias, coronary blood flow, and systemic vascular resistance during severe regional ischaemia and reperfusion in an open chest pig model.

\section{Methods}

Male pigs (Large White crossed with Landrace), weighing 27-30 kg, received ketamine $10 \mathrm{mg} / \mathrm{kg}$, atropine $0.5 \mathrm{mg}$, and diazepam $1 \mathrm{mg} / \mathrm{kg}$ intramuscularly as premedication. Anaesthesia was induced with thiopentone (thiopental) sodium $250 \mathrm{mg}$ intravenously. The pigs were ventilated with a nitrous oxide/oxygen mixture (volume ratio 4:6), to which $0.5-1.5 \%$ of isoflurane was added. The $\mathrm{PO}_{2}$ was controlled between $100-140 \mathrm{~mm} \mathrm{Hg}$ and the $\mathrm{pH}$ between 7.43 and 7.48. Standard limb lead ECG and arterial pressure were monitored continuously.

The heart was exposed by a midsternal thoracotomy. The main stem of the left coronary artery was dissected free for about $3 \mathrm{~mm}$ at a point one half to two thirds of the way from its origin to its apical termination. Ligation was effected by abrupt tightening of a piece of polyvinyl tubing around a $2 \mathrm{~cm}$ length of rigid tubing placed alongside the artery. This procedure was used to facilitate reperfusion after 30 minutes of ischaemia. An ultrasonic flow probe (Transonic Systems, Ithaca, New York, USA) was placed around the aortic root to determine the cardiac output. The systemic vascular resistance was calculated in dynes.s. $\mathrm{cm}^{-5}$ from the mean arterial pressure and the cardiac output. $^{18}$

Ventricular fibrillation was defined according to Katz. ${ }^{19}$ Epicardial direct current shock of increasing current strength was applied usually within four seconds of the onset of arrhythmias. If defibrillation could not be accomplished within 90 seconds, the experiment was terminated. Ventricular tachycardia was defined as more than four consecutive uniform or multiform ventricular premature systoles. Runs of ventricular tachycardia were considered terminated when they were followed by at least three normally conducted sinus beats.

In addition to the recording of the incidence of ischaemic/reperfusion arrhythmias, the ventricular fibrillation threshold was measured shortly before as well as three minutes after coronary artery ligation. An electrical stimulus consisting of a train of 10 square wave pulses was triggered by the $\mathrm{R}$ wave and distributed over $210 \mathrm{~ms}$ during the $\mathrm{T}$ wave. The stimulus was passed between two platinum electrodes sutured onto the anterior wall of the left and right ventricle, $2.5 \mathrm{~cm}$ apart. The anode was placed over the border of the expected ischaemic zone in the left ventricle and the cathode over the non-ischaemic zone of the right ventricle. Pulses were generated using a Grass S88 stimulator. The stimulus current was progressively increased in $2 \mathrm{~mA}$ steps, starting at $4 \mathrm{~mA}$, until ventricular fibrillation occurred. The ventricular fibrillation threshold was taken as the lowest current required to induce ventricular fibrillation. Care was taken not to use a long train of pulses, which may spill over into the late portion of the $\mathrm{T}$ wave (refractory phase) ${ }^{20}$ Epicardial direct current shock was applied usually within four seconds of the onset of ventricular fibrillation and repeated if necessary. The ventricular fibrillation threshold was measured before coronary artery ligation, five minutes after coronary artery ligation, and 10 minutes after reperfusion. Runs of ventricular fibrillation or ventricular tachycardia were considered terminated when they were followed by at least three normally conducted sinus beats. Thirty minutes after ligation the ligature was released to reperfuse.

Left ventricular pressures and the maximum rate of pressure development in the left ventricle $\left(\mathrm{LV}_{\max } \mathrm{dP} / \mathrm{dt}\right)$ were measured using a tip transducer catheter placed in the left ventricular cavity (Millar, Houston, Texas, USA) and connected to a Cardiomax computerised system (Columbus Instruments, Columbus, Ohio, USA).

Regional left ventricular blood flow was measured 23 minutes after initiation of intravenous drug administration (seven minutes before ligation), 20 minutes after coronary artery ligation, as well as 20 minutes after reperfusion. The reference sample method was employed. The radionuclides used were ${ }^{95}$ niobium, ${ }^{51}$ chromium, and ${ }^{103}$ ruthenium (New England Nuclear, Boston, Massachusetts, USA). Full details of this procedure have been published. ${ }^{21} 22$ Radionuclides were used in five placebo and five levosimendan treated animals to determine ventricular blood flow.

Microdrill biopsies were taken 12 minutes after coronary artery ligation. These biopsies were obtained from the peripheral ischaemic and non-ischaemic zones of the left ventricular wall using a modified dental drill. Biopsies were predominantly subepicardial and were frozen in liquid nitrogen within four seconds. They were then extracted in perchloric acid and neutralised. Tissue extracts were analysed for 
$0.08 \mathrm{mg} / \mathrm{kg}$ levo

orally twice daily

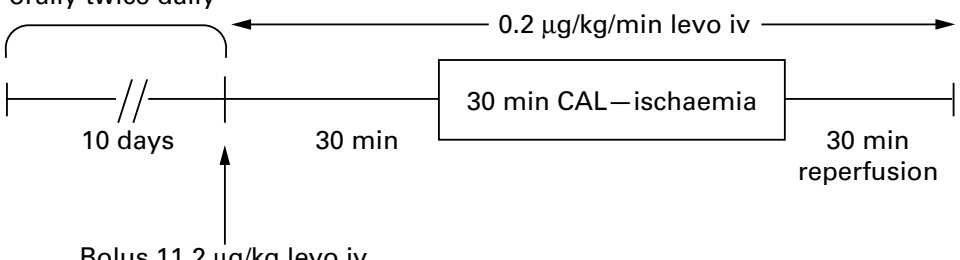

Bolus $11.2 \mu \mathrm{g} / \mathrm{kg}$ levo iv

Figure 2 Diagrammatic representation of the experimental protocol. Animals were treated with levosimendan (levo) orally for 10 days. Thirty minutes before coronary artery ligation $(C A L)$, animals were given a bolus dose of levosimendan intravenously, followed by a continuous infusion throughout coronary artery ligation and reperfusion.

ATP, phosphocreatine, and cAMP as previously described. ${ }^{22}$

Thirty minutes after reperfusion the left coronary artery was ligated at the same site and the ischaemic zone delineated by injection of patent blue dye into the left atrium, as described. ${ }^{23}$ The size of the ischaemic zone was expressed as a percentage of the total left ventricular mass. When the underperfused (ischaemic) zone was less than $26 \%$ or more than $34 \%$ of the left ventricular mass the heart was excluded from the study.

\section{STUDY GROUPS}

Levosimendan group (13 pigs)

In order to obtain stable plasma levosimendan concentrations and to observe the effect of chronic levosimendan treatment on the inotropic efficacy of the drug, pigs received levosimendan in gelatine capsules, $0.08 \mathrm{mg} / \mathrm{kg}$ orally twice daily for 10 days. On the day of the experiment (day 11), starting 30 minutes before ligation, levosimendan $11.2 \mu \mathrm{g} / \mathrm{kg}$ was given as an intravenous bolus dose over 10 minutes followed by a continuous infusion of $0.2 \mu \mathrm{g} / \mathrm{kg} / \mathrm{min}$ throughout ischaemia and reperfusion (fig 2). Levosimendan was dissolved in $4 \mathrm{mM}$ sodium hydroxide and diluted with $0.9 \%$ saline. In a dose finding study done by us, this dose regimen resulted in an approximately $20 \%$ increase in contractile activity, as measured by the $\mathrm{LV}_{\max } \mathrm{dP} / \mathrm{dt}$.

\section{Placebo group (9 pigs)}

The pigs were given gelatine capsules containing dextrose, twice daily for 10 days. On the day of the experiment and before coronary artery ligation, vehicle was injected over 10 minutes followed by a continuous infusion for the remainder of the experiment (80 minutes).
PLASMA CONCENTRATIONS OF LEVOSIMENDAN Arterial blood was collected to determine the plasma levosimendan concentration before the infusion, at 22 minutes after starting the infusion, at 15 minutes after coronary artery ligation, and at 27 minutes after reperfusion. Plasma levosimendan measurements were undertaken by Orion Pharma, Espoo, Finland.

\section{CALCULATIONS}

Rate-pressure product $(\mathrm{mm} \mathrm{Hg} / \mathrm{min} / \mathrm{kg})=$ heart rate $\times$ systolic arterial pressure/body weight $(\mathrm{kg})$.

Mean arterial pressure $(M A P)(\mathrm{mm} \mathrm{Hg})=(\mathrm{SAP}$ $+2 \mathrm{DAP}) / 3$, where SAP = systolic arterial pressure and DAP = diastolic arterial pressure.

Systemic vascular resistance $\left(\right.$ dyne. $\left.\mathrm{s}^{-1} \cdot \mathrm{cm}^{-5}\right)=80$ $\times \mathrm{MAP} / \mathrm{CO}$, where $\mathrm{CO}=$ cardiac output.

\section{STATISTICS}

Results are presented as mean (SD). Tissue values are expressed as units/g fresh weight. One way analysis of variance (ANOVA) was applied using paired analysis where appropriate. Fisher's exact test was used to compare the incidence of ventricular arrhythmias during ischaemia/reperfusion. Bonferroni's correction was applied to compensate for multiple comparisons $^{24}$. A probability value of $\mathrm{p}<0.05$ was considered significant.

\section{Results}

\section{HAEMODYNAMIC CHANGES}

In comparison with control animals, chronic oral treatment with levosimendan increased the cardiac output (2.04 (0.25) v 2.45 (0.55) 1/ min, $\mathrm{p}<0.05)$ and decreased the systemic vascular resistance $(2745$ (244) v 2248 (212) dyne. $\mathrm{s}^{-1} \cdot \mathrm{cm}^{-5}, \mathrm{p}<0.05$ ) (table 1). Myocardial contractility was, however, unchanged by the 10 day oral treatment with levosimendan. These measurements were performed before starting the bolus dose infusion of levosimendan.

Cardiac output in the levosimendan group was higher and systemic vascular resistance lower throughout the experiments. Heart rates were similar in the placebo and treated groups throughout the experiment. Systemic vascular resistance (calculated) was lower in the levosimendan group throughout ischaemia and reperfusion (table 1 ).

Levosimendan infusion, started 30 minutes before coronary artery ligation, increased the maximum rate of left ventricular pressure

Table 1 Haemodynamic effects of levosimendan

\begin{tabular}{|c|c|c|c|c|c|c|}
\hline \multirow[b]{2}{*}{ Variable } & \multicolumn{2}{|c|}{ Preischaemia (18 min after infusion) } & \multicolumn{2}{|c|}{ Ischaemia (25 min) } & \multicolumn{2}{|c|}{ Reperfusion (10 min) } \\
\hline & Placebo & Levosimendan & Placebo & Levosimendan & Placebo & Levosimendan \\
\hline Cardiac output (1/min) & $2.1(0.3)$ & $2.5(0.2)^{\star}$ & $2.0(0.2)$ & $2.6(0.5)^{\star}$ & $2.0(0.1)$ & $2.6(0.4)^{\star}$ \\
\hline Heart rate (beats/min) & $80(8)$ & $93(23)$ & $92(10)$ & $104(21)$ & $96(20)$ & $112(17)$ \\
\hline Stroke volume $(\mathrm{ml})$ & $28.3(0.3)$ & $30.0(0.25)$ & $21.0(3.3)$ & $30.4(1.5)+$ & $21.5(4.8)$ & $23.3(4.4)$ \\
\hline Systemic vascular resistance $\left(\right.$ dyne. $\mathrm{s}^{-1} \cdot \mathrm{cm}^{-5}$ ) & $2808(209)$ & $2293(348)^{\star}$ & $2669(424)$ & $2024(188) \dagger$ & $2685(66)$ & $2274(293)$ \\
\hline Mean arterial pressure $(\mathrm{mm} \mathrm{Hg})$ & $70(8)$ & $69(7)$ & $66(7)$ & $62(9)$ & $68(7)$ & $68(11)$ \\
\hline $\mathrm{LV}_{\mathrm{m}} \mathrm{dP} / \mathrm{dt}(\mathrm{pos})(\mathrm{mm} \mathrm{Hg} / \mathrm{s})$ & $817(129)$ & $972(116) \dagger$ & $806(151)$ & $925(91) \ddagger$ & $784(130)$ & $956(118)^{\star}$ \\
\hline $\mathrm{LV}_{\max } \mathrm{dP} / \mathrm{dt}(\mathrm{neg})(\mathrm{mm} \mathrm{Hg} / \mathrm{s})$ & $1148(240)$ & $1198(254)$ & $1022(162)$ & $945(92)$ & $1110(182)$ & $956(282)$ \\
\hline LV peak systolic pressure (mm Hg) & $76(11)$ & $75(6)$ & $69(7)$ & $71(7)$ & $74(10)$ & $74(14)$ \\
\hline Rate-pressure product $(\mathrm{mm} \mathrm{Hg} / \mathrm{min} / \mathrm{kg})$ & $302(22)$ & $317(28)$ & $300(18)$ & $338(37)$ & $303(15)$ & $345(19)$ \\
\hline
\end{tabular}

Values are mean (SD).

${ }^{\star} \mathrm{p}<0.05, \mathrm{tp}<0.005 v$ placebo; $\neq \mathrm{p}=0.0937 v$ placebo

$\mathrm{LV}$, left ventricular; $\mathrm{LV}_{\max } \mathrm{dP} / \mathrm{dt}$ (neg), maximum rate of relaxation of the left ventricle; $\mathrm{LV}_{\max } \mathrm{dP} / \mathrm{dt}$ (pos), maximum rate of contraction of the left ventricle. 


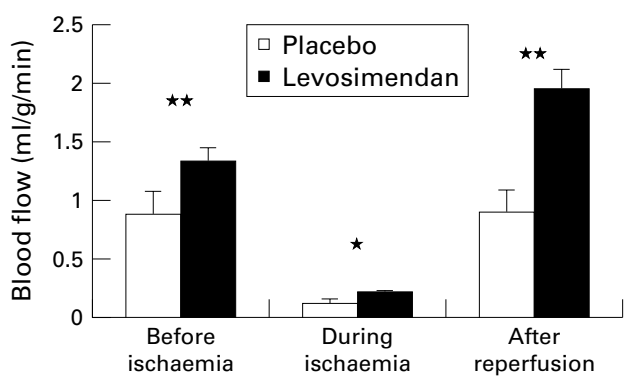

Figure 3 Levosimendan increased blood flow in the peripheral ischaemic zone of the left ventricle before coronary artery ligation (before ischaemia) and during ischaemia and after reperfusion when compared with placebo treated hearts. The peripheral ischaemic zone was defined as the unstained (with patent blue) outer border of the ischaemic zone in the left ventricle. The ischaemic zone was delineated at the end of each experiment by injection of patent blue dye into the left atrium. ${ }^{\star} p<0.05 ;{ }^{\star *} p<0.001(n=5)$.

development $\left(\mathrm{LV}_{\max } \mathrm{dP} / \mathrm{dt}\right)$ in the preligation period $(817$ (129) $\mathrm{mm} \mathrm{Hg} / \mathrm{s}$ in the placebo group $v 972(116) \mathrm{mm} \mathrm{Hg} / \mathrm{s}$ in the levosimendan group, $\mathrm{p}<0.05)$. During ischaemia the $\mathrm{LV}_{\max } \mathrm{dP} / \mathrm{dt}$ returned to preinfusion values. Levosimendan prevented the decline in $\mathrm{LV}_{\max } \mathrm{dP} / \mathrm{dt}$ associated with reperfusion in the placebo group (784 (130) $\mathrm{mm} \mathrm{Hg} / \mathrm{s}$ in the placebo group $v 956(118) \mathrm{mm} \mathrm{Hg} / \mathrm{s}$ in the levosimendan group, $\mathrm{p}<0.05)$. This improvement in contractility was lost by 25 minutes of reperfusion, when $\mathrm{LV}_{\max } \mathrm{dP} / \mathrm{dt}$ was 877 (146) $\mathrm{mm} \mathrm{Hg} / \mathrm{s}$ in control animals and 923 (170) $\mathrm{mm} \mathrm{Hg} / \mathrm{s}$ in levosimendan treated animals. The maximum rates of left ventricular relaxation $\left(\mathrm{LV}_{\max } \mathrm{dP} / \mathrm{dt}\right.$ neg), left ventricular systolic pressure, and mean arterial pressures were similar in the two groups.

Maximum rates of left ventricular relaxation $\left(\mathrm{LV}_{\max } \mathrm{dP} / \mathrm{dt}(\mathrm{neg})\right)$ were unchanged by levosimendan. By 25 minutes of reperfusion, $\mathrm{LV}_{\max } \mathrm{dP} / \mathrm{dt}$ (neg) was -1147 (174) $\mathrm{mm} \mathrm{Hg} / \mathrm{s}$ for control hearts and -1013 (212) $\mathrm{mm} \mathrm{Hg} / \mathrm{s}$ for levosimendan treated hearts.

REGIONAL LEFT VENTRICULAR BLOOD FLOW Levosimendan increased blood flow in the left ventricle before coronary artery ligation (1.32 (0.20) $v 0.86(0.13) \mathrm{ml} / \mathrm{g} / \mathrm{min}, \mathrm{p}<0.001$ ) (fig $3)$. During the ischaemic and reperfusion periods these higher blood flow rates were maintained in the levosimendan group.

INCIDENCE OF VENTRICULAR ARRHYTHMIAS Data on ventricular arrhythmias are given in table 2 .
Ventricular tachycardia

There were no statistical differences in the incidence of ventricular tachycardia between the two groups during ischaemia and reperfusion.

\section{Ventricular fibrillation}

In the ischaemic period, sinus rhythm could not be restored by defibrillation in four pigs in the levosimendan group. In a fifth pig, successful defibrillation was obtained within 90 seconds. In the placebo group only one pig had ventricular fibrillation, which was successfully defibrillated.

In the reperfusion period, ventricular fibrillation in one pig was intractable in the levosimendan group. In another six pigs which developed ventricular fibrillation, sinus rhythm could be restored. In the placebo group, the five pigs with ventricular fibrillation were successfully defibrillated.

VENTRICULAR FIBRILLATION THRESHOLD

Levosimendan had no effect on the ventricular fibrillation threshold. Before coronary artery ligation the threshold in the levosimendan group was $15.4(4.0) \mathrm{mA}(\mathrm{n}=10)$ and in the placebo group, 21.4 (6.0) $\mathrm{mA}$. Three minutes after ligation the ventricular fibrillation threshold in the levosimendan group was decreased by $3.2(4.0) \mathrm{mA}$ and in the placebo group by $7.2(6.0) \mathrm{mA}$.

TISSUE METABOLIC CHANGES DURING ISCHAEMIA Levosimendan did not have any effect on left ventricular tissue ATP and phosphocreatine concentrations when compared with control hearts (table 3). Cyclic AMP concentrations in the two groups were similar, with increased values in the ischaemic tissue of both groups.

PLASMA CONCENTRATIONS OF LEVOSIMENDAN AND ITS METABOLITES

Plasma concentrations of levosimendan were stable throughout ischaemia $(29.5(4.5) \mathrm{ng} / \mathrm{ml})$ and reperfusion (27.1 (4.9) $\mathrm{ng} / \mathrm{ml})$. Plasma concentrations of the one levosimendan metabolite, OR-1855, were negligible (2.4$3.4 \mathrm{ng} / \mathrm{ml}$ ) throughout the experiments, while the other active metabolite, OR-1896, was not found in the plasma at all.

SIZE OF THE ISCHAEMIC ZONE

One pig from the levosimendan group was excluded because the size of the ischaemic zone

Table 2 Incidence of spontaneous ventricular arrhythmias

\begin{tabular}{|c|c|c|c|c|c|c|c|}
\hline & \multicolumn{3}{|c|}{ Ventricular tachycardia } & \multicolumn{3}{|c|}{ Ventricular fibrillation } & \multirow{2}{*}{$\begin{array}{l}V T \text { and } V F \\
\text { Total }\end{array}$} \\
\hline & Sustained & Not sustained & Total & $\begin{array}{l}\text { Successful } \\
\text { defibrillation }\end{array}$ & Intractable & Total & \\
\hline \multicolumn{8}{|l|}{ During ischaemia } \\
\hline Levosimendan & $0 / 12$ & $3 / 12$ & $3 / 12$ & $1 / 12$ & $4 / 12 \dagger$ & $5 / 12$ & $8 / 12^{\star}$ \\
\hline Placebo & $0 / 9$ & $0 / 9$ & $0 / 9$ & $1 / 9$ & $0 / 9$ & $1 / 9$ & $1 / 9$ \\
\hline \multicolumn{8}{|c|}{ During reperfusion } \\
\hline Levosimendan & $2 / 8$ & $2 / 8$ & $4 / 8$ & $6 / 8$ & $1 / 8$ & $7 / 8$ & $7 / 8$ \\
\hline Placebo & $4 / 9$ & $4 / 9$ & $8 / 9$ & $5 / 9$ & $0 / 9$ & $5 / 9$ & $8 / 9$ \\
\hline
\end{tabular}

${ }^{\star} \mathrm{p}<0.05$ v placebo.

tAll four episodes immediately followed the measurement of the ventricular fibrillation threshold by electrical stimulation Sustained, runs lasting $>30$ seconds; not sustained, runs lasting $<30$ seconds; intractable, sinus rhythm could not be restored within 90 seconds; VF ventricular fibrillation; VT, ventricular tachycardia. 
Table 3 Left ventricular tissue metabolites during the ischaemic period

\begin{tabular}{lllllll}
\hline & \multicolumn{2}{l}{ Levosimendan } & & \multicolumn{2}{l}{ Placebo } \\
\cline { 2 - 3 } & Ischaemic & Non-ischaemic & & Ischaemic & Non-ischaemic \\
\hline Cyclic AMP $(\mathrm{nmol} / \mathrm{g})$ & $0.82(0.24)^{\star}$ & $0.59(0.18)$ & & $0.71(0.09)^{\star}$ & $0.53(0.11)$ \\
ATP $(\mu \mathrm{mol} / \mathrm{g})$ & $1.88(1.85)^{\star}$ & $3.19(2.14)$ & & $2.39(1.37)^{\star}$ & $3.08(1.77)$ \\
$\operatorname{PCr}(\mu \mathrm{mol} / \mathrm{g})$ & $1.86(2.56)^{\star \star}$ & $8.82(6.60)$ & & $6.00(3.60)^{\star \star}$ & $11.09(5.45)$
\end{tabular}

Values are mean $(\mathrm{SD})$

${ }^{\star} \mathrm{p}<0.05,{ }^{\star \star} \mathrm{p}<0.01 v$ non-ischaemic zone.

AMP, adenosine monophosphate; ATP, adenosine triphosphate; ischaemic, peripheral ischaemic zone; PCr, phosphocreatine.

was too large. Mean size of the ischaemic zone in the levosimendan group was $28.8(2.8) \%$ and in the placebo group, 28.5 (3.3)\%.

\section{Discussion}

Levosimendan is a unique calcium sensitiser that binds to myocardial troponin $\mathrm{C}$ and facilitates the activation of the contractile apparatus by calcium. In addition, levosimendan opens the ATP sensitive potassium channel in both vascular smooth muscle ${ }^{12}$ and ventricular myocytes. ${ }^{11}$ A previous study from our laboratory showed that levosimendan improved reperfusion function without increasing the incidence of arrhythmias in the isolated guinea pig model of global ischaemia. ${ }^{17}$ In the present study, using an in vivo large animal model, levosimendan increased ischaemic and reperfusion cardiac output and preischaemic and reperfusion left ventricular contractility $\left(\mathrm{LV}_{\max } \mathrm{dP} / \mathrm{dt}\right)$. However, it also increased the number of arrhythmic events during ischaemia in this model of regional ischaemia. Levosimendan increased coronary flow and decreased systemic vascular resistance throughout the study. These secondary vasodilator properties would be expected to produce further improvement in ischaemic and reperfused function by virtue of their anti-ischaemic affects in the heart.

Because the ischaemic myocardium copes poorly with raised calcium concentrations (either intracellular or extracellular), ${ }^{25-27} \mathrm{cal}-$ cium sensitisers could be particularly effective in the treatment of the ischaemic and reperfused heart. These compounds do not increase the already raised calcium concentrations in the ischaemic myocardium, and this would be expected to reduce the risk of further exacerbating the cytosolic calcium overload induced by ischaemia and reperfusion. Calcium sensitisers should also be electrophysiologically "silent" - that is, they should not cause electrophysiological manifestations that may predispose the heart to arrhythmias. ${ }^{28}$

\section{HAEMODYNAMIC CHANGES INDUCED BY} LEVOSIMANDAN

Levosimendan improved cardiac output both during ischaemia and reperfusion in this study. This increase in cardiac output is probably a result of improved contractility (left ventricular $\mathrm{dP} / \mathrm{dt}$ ) and a reduction in systemic vascular resistance in the levosimendan treated animals. Despite the fact that levosimendan did not increase contractility during ischaemia, stoke volume was higher in levosimendan treated hearts than in the placebo group. This increase in stroke volume was not caused by a reduction in heart rate in these animals (table 1). The difference in stroke volume between the two groups is because of an ischaemia induced decrease in stroke volume in the placebo hearts. Levosimendan treatment prevented this ischaemia induced reduction in stroke volume observed in the placebo treated animals.

Contractility $\left(\mathrm{LV}_{\max } \mathrm{dP} / \mathrm{dt}\right)$ is an index of velocity of contraction and is largely independent of the preload/systemic vascular resistance to which the heart is subject ${ }^{25}$. In this study, $\mathrm{LV}_{\max } \mathrm{dP} / \mathrm{dt}$ was at its lowest shortly after reperfusion under control conditions (table 1). Levosimendan, however, greatly improved the contractility of the heart early in reperfusion. These data support our proposal that the improved cardiac output observed with levosimendan treatment is not merely the result of a decreased systemic vascular resistance, but also reflects improved contractile function of these hearts. These results confirm our earlier findings in an isolated guinea heart model. ${ }^{17}$

VASODILATOR PROPERTIES OF LEVOSIMENDAN A pronounced coronary ${ }^{13} 29$ and peripheral ${ }^{29}$ vasodilator effect of levosimendan has been described in previous studies. Recent electrophysiological studies with levosimendan suggest that these vasodilator effects are mediated through opening of the ATP sensitive potassium channel in vascular smooth muscle cells. ${ }^{12}$ These vascular effects of levosimendan would be expected not only to increase blood flow to the underperfused myocardium, but also to reduce the afterload on the heart. The aim of various haemodynamic treatments used in heart failure is to reduce the afterload on the heart, which would be expected to improve myocardial performance by allowing better left ventricular emptying, reducing end diastolic volume, and consequently reducing end diastolic preload. ${ }^{25}$

LEVOSIMENDAN AND VENTRICULAR ARRHYTHMIAS A major concern with the clinical use of conventional inotropic agents has been that they tend to be proarrhythmic, possibly because they promote the formation of tissue cAMP, either by $\beta$ adrenergic stimulation or by phosphodiesterase inhibition. Because only high concentrations of levosimendan (more than $90 \mathrm{ng} / \mathrm{ml}$ ) are thought to inhibit phosphodiesterase-III, ${ }^{30}{ }^{31}$ we believe that inhibition of phosphodiesterase activity by levosimendan can be ruled out in our study as plasma concentrations never exceeded $30 \mathrm{ng} /$ $\mathrm{ml}$. In addition, although tissue cAMP concentrations were raised in the ischaemic region of the levosimendan treated hearts, this increase was similar in both treatment and control groups. The ischaemia induced increase in tissue cAMP is a well described phenomenon not yet fully understood. ${ }^{20}{ }^{21}$

The effect of levosimendan on the incidence of arrhythmias has been reported in a limited number of studies such as ours ${ }^{17}$ and that of Nijhawan and colleagues, ${ }^{16}$ in conditions where hearts were subjected to global ischaemia. In both studies levosimendan was found to have 
no effect on the incidence of arrhythmias, either during ischaemia or reperfusion. The difference in the effect of levosimendan on the incidence of ischaemic arrhythmias observed in this study may be explained by the difference in the models of ischaemia. We know that hearts subjected to regional ischaemia are more prone to arrhythmias owing to the inhomogeneity of the myocardium over the ischaemic and non-ischaemic zone of these hearts.

\section{MYOCARDIAL METABOLISM}

The increase in blood flow to the ischaemic zone by levosimendan would be expected to reduce ischaemic damage by preserving the energy status of the heart. ${ }^{32}$ In addition, opening of the ATP sensitive potassium channel has been linked to an increase in tissue viability. In this study, however, tissue ATP and phosphocreatine contents remained unchanged. Our results are in contrast with those obtained in two other studies where levosimendan reduced ischaemic damage as measured by epicardial nicotinamide adenine dinucleotide phosphate (NADH) fluorescence photography ${ }^{34}$ and high energy phosphate compounds. ${ }^{17}$ The reason for this may be the severity of ischaemia in the pig heart following coronary artery ligation. ${ }^{35}$ Despite the levosimendan induced improvement in blood flow to the peripheral ischaemic zone (during ischaemia), residual blood flow was only about $12 \%$ of the preligation value.

\section{STUDY LIMITATIONS}

A reservation about this study was that the anaesthesia caused a significant reduction in myocardial function. Our group had changed from $\alpha$ chloralose $^{36}$ to isoflurane as the preferred anaesthetic agent, ${ }^{23}$ and decided to continue using this form of anaesthesia in the current study. $\alpha$ Chloralose caused an increase in heart rate, which we felt could influence the susceptibility of the heart to arrhythmias during ischaemia and reperfusion. These heart rate effects are not seen when animals are anaesthetised with isoflurane. ${ }^{37}$ Although the reduction in function during anaesthesia is not ideal, we believe that because both groups of animals were subjected to the same anaesthesia, the data obtained in the study are valid.

\section{CONCLUSIONS}

To our knowledge, this is the first study to describe the effects of levosimendan in an in vivo model of severe regional ischaemia followed by reperfusion. Levosimendan improved cardiac output throughout the experiment, and improved contractility before ischaemia and during reperfusion. However, it unexpectedly increased the number ischaemic arrhythmias in this model of severe regional ischaemia. Levosimendan should therefore be used with caution in patients who have conditions associated with regional myocardial ischaemia. In future when more human safety data are available, this caveat may be confirmed or set aside.
We would like to thank the MRC of South Africa and the University of Cape Town for ongoing support and Dr H Haikala of Orion Pharma, Finland for additional support and supplies of levosimendan.

1 Opie LH, Nathan D, Lubbe WF. Biochemical aspects of arrhythmogenesis and ventricular fibrillation. Am f Cardiol 1979;43:131-48.

2 Clusin WT, Bristow MR, Karagueuzian HS, et al. Do calcium-dependent ionic currents mediate ischemic ventricular fibrillation. Am 7 Cardiol 1982;49:606-12.

3 Opie LH, Coetzee WA, Dennis SC, et al. A potential role of calcium ions in early ischemic and reperfusion arrhythmias. Ann NY Acad Sci 1988;522:464-77.

4 Opie LH, Coetzee WA. Role of calcium ions in reperfusion arrhythmias: relevance to pharmacological intervention. Cardiovasc Drugs Ther 1988;2:623-36.

5 Solaro RJ, Moir AGJ, Perry SV. Phosphorylation of troponin $I$ and the inotropic effect of adrenaline in the perfused rabbit heart. Nature 1976;262: 615-6.

6 Abe Y, Kitada Y, Narimatsu A. Effects of a calcium sensitizing positive inotropic agent MCI-154 and its combined use with analapril on post-ischaemic contractile dysfunction of dog hearts. F Cardiovasc Pharmacol 1995;26:653-9.

7 De Zeeuw S, Trines SA, Krams R, et al. Cardiovascular profile of the calcium sensitizer EMD 57033 in open chest anaesthetised pigs with regionally stunned myocardium. $\mathrm{Br}$ 7 Pharmacol 2000;129:1413-22.

8 Soei LK, Sassen LMA, Fan DS, et al. Myofibrillar $\mathrm{Ca}^{2+}$ sensitisation predominantly enhances function and mechanisitisation predominantly enhances function and mechani-
cal efficacy of stunned myocardium. Circulation 1994;90: cal efficacy

9 Haikala H, Levijoki J, Linden I-B. Troponin C mediated calcium sensitization by levosimendan accelerates the proportional development of isometric tension. $7 \mathrm{Mol} \mathrm{Cell} \mathrm{Car-}$ diol 1995;27:2155-65

10 Haikala H, Nissinen E, Etemadzadeh E, et al. Troponin $\mathrm{C}$-mediated calcium sensitization induced by levosimendan does not impair relaxation. $f$ Cardiovasc Pharmacol 1995;25:794-801.

11 Yokoshiki H, Katsube Y, Sunagawa M, et al. The novel calcium sensitizer levosimendan activates the ATP-sensitive potassium channel in rat ventricular cells. F Pharmacol Exp Ther 1997;283:375-83.

12 Yokoshiki H, Katsube Y, Sunagawa M, et al. Levosimendan, a novel $\mathrm{Ca}^{2+}$ sensitizer, activates the glibenclamide-sensitive $\mathrm{K}^{+}$channel in rat arterial myocytes. Eur f Pharmacol 1997; 333:249-59.

13 Zimmermann N, Boknik P, Gams E, et al. Calcium sensitisation as a new principle of inotropic therapy in end-stage
heart failure? Eur 7 Cardiothorac Surg 1998;14:70-5.

14 Hasenfuss G, Pieske B, Castell M, et al. Influence of the novel inotropic agent levosimendan on isometric tension and calcium cycling in failing human myocardium. Circulation 1998;98:2141-7.

15 Lilleberg J, Niemenen MS, Akkila J, et al. Effects of a new calcium sensitiser, levosimendan, on haemodynamics, coronary blood flow and myocardial substrate utilization early after coronary artery bypass grafting. Eur Heart f 1998;19: 660-8.

16 Nijhawan N, Nicolosi AC, Montgomery MW, et al. Levosimendan enhances cardiac performance after cardiopulmonary bypass: a prospective, randomized placebocontrolled trial. $\mathcal{F}$ Cardiovasc Pharmacol 1999;34:219-28.

17 Du Toit EF, Muller CA, McCarthy J, et al. Levosimendan: effects of a calcium sensitizer on function and cyclic nucleotide levels during ischemia/reperfusion in the Langendorff otide levels during ischemia/reperfusion in the Langendorff perfused 14 .

18 Lilleberg J, Sundberg S, Haeyhae M, et al. Haemodynamic dose-efficacy of levosimendan in healthy volunteers. Eur $\mathcal{F}$ Clin Pharmacol 1994;47:267-74.

19 Katz AM. Physiology of the heart. New York: Raven Press, 1977:324.

20 Lubbe WF, Podzuweit T, Daries PS, et al. The role of cyclic adenosine monophosphate in adrenergic effects on ventricular vulnerability to fibrillation in the isolated perfused rat heart. F Clin Invest 1978;61:1260-9.

21 Lubbe WF, Peisach M, Pretorius R, et al. Distribution of myocardial blood flow before and after coronary artery ligation in the baboon. Relation to early ventricular fibrillation. Cardiovasc Res 1974;8:478-87.

22 Muller CA, Opie LH, Hamm CW, et al. Prevention of ventricular fibrillation by metoprolol in a pig model of acute myocardial ischemia: absence of a major arrhythmogenic myocardial ischemia: absence of a major arrhythmogenic
role for cyclic AMP. $₹ \mathrm{Mol}$ Cell Cardiol 1986;18:375-87.

23 Muller CA, Opie LH, Pineda CA, et al. Combination of a calcium antagonist, verapamil, with an angiotensin converting enzyme inhibitor, trandolapril, in experimental myocardial ischaemia and reperfusion: antiarrhythmic and hemodynamic effects of chronic oral pretreatment. Cardiovasc Drugs Ther 1998;12:449-55.

24 Wallenstein S, Zucker CL, Fleiss JL. Some statistical methods useful in circulation research. Circ Res 1980;47:1-9.

25 Opie LH. The heart, 3rd ed. New York: Raven Press, 1998:301-38

26 Krause S, Jacobus WE, Becker LC. Alterations in cardiac sarcoplasmic reticulum calcium transport in the postischemic "stunned" myocardium. Circ Res 1989;65:52630.

27 Gao WD, Atar D, Backx PH, et al. Relationship between intracellular calcium and contractile force in stunned myointracellular calcium and contractile
cardium. Circ Res 1995;76:1036-48. 
28 Varro A, Papp JG. Classification of positive inotropic actions based on electrophysiologic characteristics: where should calcium sensitizers be placed? I Cardiovasc Pharmacol 1995;26:S32-44

29 Pagel PS, Harkin CP, Hettrick DA, et al. Levosimendan (OR-1259), a myofilament calcium sensitizer, enhances myocardial contractility but does not alter isovolumic relaxation in conscious and anesthetized dogs. Anesthesiology 1994;81:974-87.

30 Sandell E-P, Hayha M, Antila S, et al. Pharmacokinetics of levosimendanosimendan in healthy volunteers and patients with congestive heart failure. 7 Cardiovasc Pharmacol 1995 26(suppl 1):S57-62.

31 Edes I, Kiss E, Kitada Y, et al. Effects of levosimendan, a cardiotonic agent targeted to troponin $\mathrm{C}$, on cardiac function and on phosphorylation and $\mathrm{Ca}^{2+}$ sensitivity of cardiac myofibrils and sarcoplasmic reticulum in guinea pig heart.

32 Grover GJ. Protective effects of ATP sensitive potassium channel openers in models of myocardial ischemia. Cardiochasc Res 1994:28:778-82.
33 Hosoda $\mathrm{H}$, Sunamori $\mathrm{M}$, Watanabe $\mathrm{M}$, et al. Effects of pinacidil combined with potassium cardioplegia on myocardial cidil combined with potassium cardioplegia on myocardial
viability in hypothermic global ischemia followed by viability in hypothermic global ischemia followe

34 Rump AFE, Acar D, Klaus W. A quantitative comparison of functional and anti-ischemic effects of the phosphodiesterase inhibitors amrinone, milrinone and levosimendan in rabbit isolated hearts. Br f Pharmacol 1994;112:757-62.

35 Hearse DJ, Muller CA, Fukanami M, et al. Regional myocardial ischemia: characterisation of temporal, transmural and lateral flow interfaces in the porcine heart. Can $\mathcal{F}$ Cardiol 1986;2:48-61.

36 Muller CA, Opie LH, Peisach M, et al. Chronic oral pretreatment with the angiotensin converting enzyme inhibitor trandolapril decreases ventricular fibrillation in acute ischemia and reperfusion. Eur Heart 7 1994;15:988

37 Thurmon JC, Tranquilli WJ. Anaesthesia for cardiovascular research. In: Stanton HC, Mersmann HJ, eds. Swine in cardiovascular research. Boca Raton: CRC press, 1986:4056.

\section{Electronic pages}

\section{eHEART: www.heartjnl.com}

The following electronic only articles are published in conjunction with this issue of Heart (see also p 38).

Effects of carvedilol on left ventricular function, mass, and scintigraphic findings in isolated left ventricular non-compaction

M Toyono, C Kondo, Y Nakajima, M Nakazawa, K Momma, K Kusakabe

A four month old infant with isolated left ventricular noncompaction was treated with carvedilol. Haemodynamic studies and various types of imaging-including echocardiography, radiographic angiography, magnetic resonance imaging, and single photon emission computed tomography with ${ }^{201} \mathrm{Tl},{ }^{123} \mathrm{I}-\beta$-methyliodophenylpentadecanoic acid (BMIPP), and ${ }^{123}$ I-metaiodobenzylguanidine (MIBG)-were performed before and 14 months after treatment. Left ventricular ejection fraction increased from $30 \%$ to $57 \%$, and left ventricular end diastolic volume, end systolic volume, and end diastolic pressure showed striking reductions during treatment. Left ventricular mass decreased to about two thirds of the baseline value after treatment. Per cent wall thickening increased after carvedilol in the segments corresponding to non-compacted myocardium. A mismatch between $\mathrm{Tl}$ and BMIPP uptake in the area of non-compaction observed before carvedilol disappeared after treatment. Impaired sympathetic neuronal function shown by MIBG recovered after treatment. Thus carvedilol had beneficial effects on left ventricular function, hypertrophy, and both metabolic and adrenergic abnormalities in isolated left ventricular non-compaction.

(Heart 2001;86:e4) www.heartjnl.com/cgi/content/full/86/ $1 / \mathrm{e} 4$
Persistence of the eustachian valve in secundum atrial septal defects: possible implications for cerebral embolism and transcatheter closure procedures

f M Strotmann, W Voelker, P Schanzenbaecher

Transcatheter closure of large secundum atrial septal defects is now accepted clinical practice. With the introduction of easily applicable closure devices the indications for this procedure have been expanded to include the closure of patent foramen ovale after cerebral stroke of unknown origin. In some of these patients a persistent eustachian valve is present. The clinical relevance of this finding is still unclear. A 36 year old patient with a brainstem stroke of unknown origin and a secundum atrial septal defect in combination with a persisting prominent eustachian valve is reported. The potential role of the eustachian valve in the genesis of the stroke and the difficulties during transcatheter closure of the defect because of the persisting valve are discussed.

(Heart 2001;86:e5) www.heartjnl.com/cgi/content/full/86/ $1 / \mathrm{e} 5$

Unusual localisation of a ventricular septal defect following blunt chest trauma

C Pierli, A Iadanza, A Del Pasqua, G Sinicropi

A 64 year old man presented with a traumatic ventricular septal defect following blunt chest trauma 40 years before. Echocardiography and left ventriculography were helpful in locating the unusual septal defect, which was subpulmonary. The shunt was small, but the anomalous chronic overload led to right ventricular failure. The surgical correction was thus too late to improve right ventricular function.

(Heart 2001;86:e6) www.heartjnl.com/cgi/content/full/86/ $1 / \mathrm{e} 6$ 